\title{
Incidence of thrombotic events and complications associated to inferior vena cava filters in patients with and without anticoagulation therapy
}

\section{Incidencia de eventos trombóticos y complicaciones asociadas al uso de filtros de vena} cava en pacientes en pacientes con o sin terapia anticoagulante

Carlos A. Hinojosa*, Sandra Olivares-Cruz, Hugo Laparra-Escareno, Zeniff Gomez-Arcive, and Javier E. Anaya-Ayala

Surgery Directorate, Division of Angiology, Vascular Surgery, and Endovascular Therapy, Instituto Nacional de Ciencias Médicas y Nutrición Salvador Zubirán. Ciudad de México, México

\begin{abstract}
Objective: Anticoagulation is the primary management to prevent venous thromboembolism; inferior vena cava filters (IVCFs) provide a mechanical prophylactic alternative when anticoagulation is contraindicated. The aim of this study was to evaltiate in IVCF patients, whether the initiation of anticoagulation therapy is associated with decreased rates of recurrent thrombotic events and device-related complications. Methods: This was a retrospective review of patients that underwent insertion of IVCF. Subjects with IVCF were studied in two groups: those initiated on anticoagulation (A) and without anticoagulation ( $(\mathrm{NA})$. Variables as indications for IVCF, anticoagulation, recurrence of thrombosis, complications, and reinterventions were examined. Results: From April 2007 to March 2014, 54 patients underwent IVCF placement; (61\% of females), with mean age of 54 years (standard deviation \pm 19$) .28(52 \%)$ were initiated on anticoagulation, during a mean follow-up period of 28 mogths, five experienced recurrent thrombosis and three were on the $A$ group $(p=0.5)$; when comparing patients that develöped post-thrombotic syndrome, seven were in the A group and seven in the NA. Two patients with IVC rupture were in the $A$ group ( $p=0.5$ ), and the only case of IVCF migration occurred in the A group. 11 (20\%) patients died from comorbiditiesmonrelated to the device or procedure (four in the A cohort). Conclusions: Patients with IVCF on anticoagulation have equivalent rates of thrombotic events and device-related complications than those patients NA.
\end{abstract}

Key words: Anticoagulation. Deep venous thrombosis. Post-thrombotic syndrome. Inferior vena cava filters. Complications. Mexico.

\section{Resumen}

Objetivo: La anticoagulación es la terapia de elección para la prevención de tromboembolismo venoso; los filtros de च̄ena cava inferior ( $F V C l)$ proveen una alternativa mecánica profiláctica cuando la anticoagulación está contraindicada. El obje tivo de este estudio fue evaluar si la terapia anticoagulante se asocia con una tasa menor de eventos trombóticos recurrentes y

Correspondence:

${ }^{*}$ Carlos A. Hinojosa

E-mail: carlos.a.hinojosa@gmail.com
Date of reception: $14-08-2018$

Date of acceptance: 10-01-2019

DOI: 10.24875/ACME.M19000064
Available online: 06-05-2019 Arch Cardiol Mex (Eng). 2019;89(3):196-201 www.archivoscardiologia.com 2604-7063/@ 2019 Instituto Nacional de Cardiología Ignacio Chávez. Published by Permanyer México. This is an open access article under the CC BY-NC-ND (http://creativecommons.org/licenses/by-nc-nd/4.0/). 
complicaciones relacionadas con el dispositivo. Métodos: Los pacientes fueron categorizados en dos grupos: Aquellos a los que se les inicio anticoagulación (A) y aquellos que no (NA). Variables tales como indicación de la colocación del filtro, anticoagulación, recurrencia de trombosis y complicaciones fueron examinadas. Resultados: De abril de 2007 a marzo 2014 , a 54 pacientes se les coloco un filtro (61\% fueron mujeres), con una media de edad de 54 años [Desviación estándar (6DE) \pm 19. Veintiocho (52\%) fueron iniciados en anticoagulación y durante un seguimiento de 28 meses, 5 pacientes experimentaron recurrencia de trombosis, 3 en el grupo $A(p=0.5)$. Al comparar los pacientes que desarrollaron síndrome posflebítico, 7 pertenecieron al grupo $A$ y 7 al grupo NA. Dos pacientes con ruptura de vena cava pertenecieron al grupo $A$ ( $p=0.5 D$ y el único caso de migración del dispositivo ocurrió en el grupo A. Once (20\%) pacientes fallecieron debido a comorbilidades no relacionadas con el dispositivo o el procedimiento. Conclusión: Pacientes con $\mathrm{FVCl}$ en anticoagulación tienen tasás de eventos trombóticos y complicaciones asociadas a los dispositivos equivalentes a aquellos pacientes sin anticoagulaciön.

Palabras clave: Anticoagulación. Trombosis venosa profunda. Síndrome posflebítico. Filtros de vena cava. Complicaciones. México.

\section{Introduction}

Venous thromboembolism (VTE) includes both, deep vein thrombosis (DVT) and pulmonary embolism (PE); the latter represents a common cause of inpatient and outpatient morbidity and mortality ${ }^{1}$. The annual incidence of VTE has been estimated from 0.1 to $0.27 \%$, affecting up to $5 \%$ of individuals of the general population at least 1 time in their life ${ }^{2}$. This entity is the result of a combination of hereditary factors as thrombophilias and acquired risk factors as hypercoagulable states that can lead to the most feared complication $\mathrm{PE}^{3}$. In this respect, it has been reported that $P E$ is the third most common cause of hospital-related death and one of the most common preventable causes ${ }^{1,3}$; approximately $20 \%$ of the affected patients die at the time of diagnosis and $11 \%$ within 3 -month period ${ }^{2}$.

Although anticoagulation remains the primary management for VTE, inferior vena cava filters (IVCFs) constitute an important alternative of mechanical prophylaxis ${ }^{4}$. The use of IVCF has increased markedly in recent years ${ }^{5}$ and, since the first device was approved in 1972, by 2012 , approximately a total of 250,000 devices had been implanted 6 . The insertion of this mechanical prophylactic modality has demonstrated to be safe; however, there are complications that may occur during the implantation and retrieval or when the filter is retained for a long time $e^{7-10}$. Although there are reasons to believe that IVCFs provide benefit for patients who cannot be initiated on anticoagulation therapy and can be lifesaving in patients at high risk of PE recurrence ${ }^{11,12}$, there are few clinical studies that have demonstrated a significant advantage of filter placement in the setting of VTE in addition to the continuation of anticoagulation ${ }^{13}$.

At the National Institute of Medical Sciences and Nutrition "Salvador Zubiran" in Mexico City, we evaluated retrospectively patients with a history of DVT and/or PE that underwent IVCF placement. To determine the value of anticoagulation, we examined the outcomes for patients with IVCF who subsequently were initiated on therapeutic levels of anticoagulation after filter placcement and compared them with those patients with $\overline{\mathrm{AV}} \mathrm{C}$ Fs that were not placed on anticoagulation.

\section{Methods}

This was a retrospective review of patients that underwent insertion of IVCF. For the purpose of our analysis, the patients were divided and studied in two groüps, those that were initiated on anticoagulation as soo as safety allowed this therapy and were compliant with the management $(A)$ and those without anticoagulation ( $\bar{N} A)$. Patients on anticoagulation were closely followed in clinic and maintained with an international normalized ratio within a therapeutic range of 2-3. Variables such as indications for filter placement, demographics, comorbidities, recurrence of thrombotic events, optimal anticoagulation therapy, development of device-related complications, post-thrombotic syndrome (PTS), and reinterventions were examined.

\section{Study setting}

Academic and Research Medical Center which is a tertiary referral facility serving a catchment area of 23 million people. Institutional review board approved this study.

\section{Statistical analysis}

Descriptive statistics were conducted; categorical data were analyzed with Cox regression test to find association of variables, Fisher exact test or likelihood ratio $x^{2}-$ was 
Table 1. Demographics and comorbidities of patients with and without anticoagulation therapy

\begin{tabular}{|c|c|c|c|c|}
\hline Variable & A group (\%) & NA group (\%) & Total & $\mathbf{p}$ \\
\hline $\begin{array}{l}\text { Gender } \\
\text { Female } \\
\text { Male }\end{array}$ & $\begin{array}{c}9(32) \\
19(68)\end{array}$ & $\begin{array}{l}12(46) \\
14(54)\end{array}$ & $\begin{array}{l}21(36) \\
33(64)\end{array}$ & $\begin{array}{l}\text { NS } \\
\text { NS }\end{array}$ \\
\hline Age (years) & 52 & 56 & & \\
\hline $\begin{array}{l}\text { Comorbidities } \\
\text { Autoimmune disease } \\
\text { SLE } \\
\text { APS } \\
\text { Wegener } \\
\text { Scleroderma } \\
\text { Protein C deficiency } \\
\text { Malignancies } \\
\text { Total of patients }\end{array}$ & $\begin{array}{c}9(32) \\
8(29) \\
2(6) \\
0(0) \\
1(4) \\
8(29) \\
28\end{array}$ & $\begin{array}{c}4(15) \\
1(4) \\
0(0) \\
2(8) \\
0(0) \\
17(65) \\
26\end{array}$ & $\begin{array}{c}13(24) \\
9(17) \\
2(4) \\
2(4) \\
1(2) \\
25(46) \\
54(100)\end{array}$ & $\begin{array}{r}0.2 \\
0.02 \\
0.4 \\
0.2 \\
\text { NS } \\
0.01\end{array}$ \\
\hline
\end{tabular}

*Statistically significant. Statistical analysis performed with Fisher's exact test. A: anticoagulation; NA: without anticoagulation; APS: antiphospholipid syndrome SLE: systemic lupus erythematosus; NS: non-significant.

Table 2. Indications for inferior vena cava filter placement in the 54 patients

\begin{tabular}{|l|c|}
\hline Indication & n (\%) \\
\hline Contraindication for anticoagulation & $24(44)$ \\
\hline Pulmonary embolism & $18(33)$ \\
\hline Anticipation for surgical procedure & $7(13)$ \\
\hline Recurrent thrombotic event & $5(9)$ \\
\hline Total (patients) & $54(100)$ \\
\hline
\end{tabular}

Table 3. Distribution of the duration of anticoagulation therapy following inferior vena cava filters placement

\begin{tabular}{|l|c|}
\hline Duration of anticoagulation & $\mathbf{n}(\%)$ \\
\hline $0-6$ months & $9(17)$ \\
\hline $6-12$ months & $5(9)$ \\
\hline$>1$ years & $1(2)$ \\
\hline Lifelong anticoagulation & $13(24)$ \\
\hline No anticoagulation & $26(48)$ \\
\hline Total (patients) & $54(100)$ \\
\hline
\end{tabular}

used with dichotomic outcomes. All tests were performed using the statistical program STATA version 14.1.

\section{Results}

From April 2007 to March 2014, a total of 54 patients with IVCF met our inclusion criteria; 33 were female $(61 \%)$, with a mean age of 54 years (range 20-85, standard deviation 19). Table 1 summarizes the patients' demographics, comorbidities, and the statistical analysis of the comparison groups. Indications for filter placement were as follows: patients with confirmed diagnosis of DVT and contraindication for anticoagulation in 24 patients (44\%), PE in $18(33 \%), 7$ individuals (13\%) underwent IVCF in anticipation for a surgical procedure that placed them at high risk for thrombotic events, and prophylactic anticoagulation was contraindicated. $5(9 \%)$ patients secondary to repeat thrombotic episodes despite optimal anticoagulation (Table-2). From these, $28(52 \%)$ were initiated on anticoagulation therapy when was safe, $13(24 \%)$ patients were placed on lifelong therapy, $9(17 \%)$ patients were placed trom 1 to 6 months period, 5 (9\%) from 6 to 12 months, $\frac{}{c}$ and 1 patient for 1 year or longer. 26 (48\%) were not plàced on anticoagulation (NA group) (Table 3). During a mean follow-up period of 28 months (standard error \pm 5 ), five patients experienced recurrent thrombotic events, $3(60 \%)$ of them were on the A group, and $2(40 \%)$ in the NA cohort $(p=0.5)$; a comparative analysis in patients that developed PTS showed that seven patients were in the A group and seven in the NA, without statistical significance for this variable: three patients developed venous ulcers, two were in the $A$, and one in the NA group $(p=0.5)$. Only three of them underwent filter removal, the period of time for IVCF removaltanged from 1 to 214 months, with a median of 24 months; in this series, the reasons for not retrieving the device were permanent filters insertion in 15 patients $(28 \%)$ and $1(2 \%)$ could not be removed due the techaical failure. The rest of patients (35) did not return to clinic or refused removal of the device. 
Table 4. Number of device-related complications and number of patients affected by post-thrombotic syndrome

\begin{tabular}{|c|c|c|c|}
\hline Complications & $A=28$ patients $(\%)$ & NA = 26 patients (\%) & $\mathbf{p}$ \\
\hline $\begin{array}{l}\text { Device related } \\
\text { IVC rupture or perforation } \\
\text { Filter migration }\end{array}$ & $\begin{array}{l}2(7) \\
1(4)\end{array}$ & $\begin{array}{c}1(4) \\
0\end{array}$ & $\begin{array}{l}0.5 \\
\text { NS }\end{array}$ \\
\hline $\begin{array}{l}\text { Other } \\
\text { Recurrent thrombosis } \\
\text { Post-thrombotic syndrome }\end{array}$ & $\begin{array}{l}3(11) \\
7(25)\end{array}$ & $\begin{array}{c}2(8) \\
7(27)\end{array}$ & $\begin{array}{l}0.5 \\
\text { NS }\end{array}$ \\
\hline
\end{tabular}

Statistical analysis performed by Fisher's exact test. IVC: inferior vena cava; A: anticoagulation; NA: without anticoagulation.

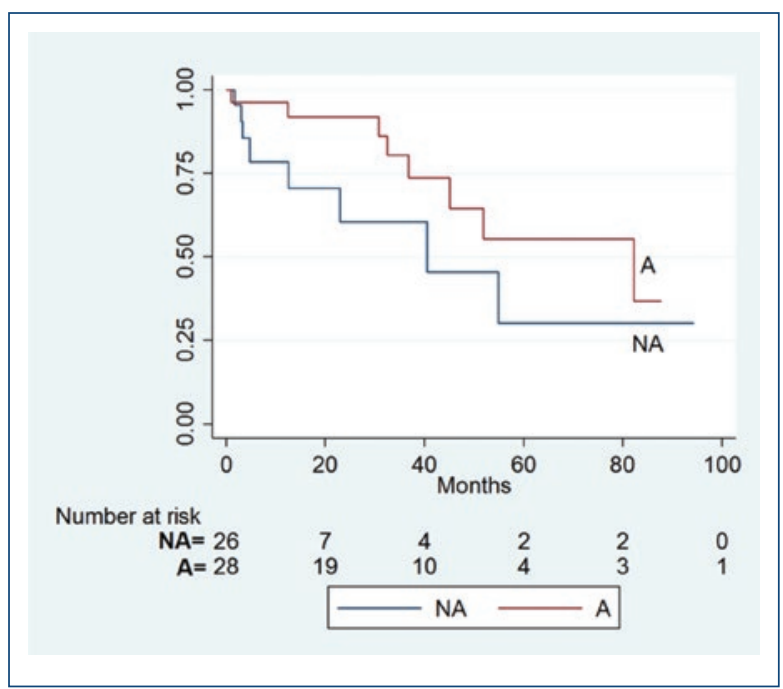

Figure 1. Kaplan-Meier estimation with respect complications rates (events) in patients with inferior vena cava filters with and without anticoagulation therapy ( $A$ and NA).

The filter that was used with more frequency was the OptEase (Cordis, Piscataway, NJ, USA) in 26 (48\%) cases, followed by Greenfield (Medi-tech/Boston Scientific, MA, USA) in 19 (35\%) and the TrapEase (Cordis, Miami Lakes, FL) in 3 patients (5\%), and finally, 2 individuals $(4 \%)$ for each of the following devices: VenaTech (B. Brain, Bethlehem, PA), Simon-Nitinol (C.R. Bard Inc., Covington, GA), and Gianturco-Roehm Bird's Nest (Cook Medical, Bloomington, Indiana), respectively. With respect to patients comorbidities associated with hypercoagulable states, $13(24 \%)$ patients had a history of systemic lupus erythematosus, $9(17 \%)$ antiphospholipid syndrome, 2 (4\%) with scleroderma and Wegener, respectively, 1 (2\%) protein C deficiency, and $25(46 \%)$ suffered from some type of malignancy. $11(20 \%)$ patients died during the follow-up period and $4(36 \%)$ of them were in the A group. With respect device-related complications and reinterventions, $2(4 \%)$ patients that experienced IVC rupture/perforation requiring surgical treatment were in the $\mathrm{A}$ gFoup $(p=0.5)$ and the only case of IVCF migration occuired in the $A$ group $(p=1)$ (Table 4). From the 28 patients maintained on anticoagulation, $23(82 \%)$ were on Vitamin $\mathrm{K}$ antagonists, 4 (14\%) placed on new oralianticoagulants, and $1(3 \%)$ patient anticoagulated with low-molecular-weight heparin (LMWH). Our analysis of Kaplan-Meier showed no difference in the number of complications and survival in patients with or NA (Fig. 1).

\section{Discussion}

There are well-recognized groups of patients whoare considered to be candidates for IVCF placement: the failed group with individuals who have experienced recurrent VTE despite optimal coagulation therapy, annther group is composed of those who have a history VTE, but who also have contraindication for anticoagulation such high risk for hemorrhagic complications or recent hemorrhage $\mathrm{e}^{4,14}$. A third group is represented of those patients who have not sustained VTE, but in whom a filter is inserted "prophylactically" in relation with a surgical procedure or event that is associalted with high incidence of thrombosis such as trauma from different causes ${ }^{15}$. Literature has reported important evidence that indicates that IVCFs effectively reduce the incidence of PE; however, as many as $76 \%$ of the study patients received concurrent anticoagulation therapy ${ }^{16}$. Conversely, the use of IVCF has been associated to adverse events and the frequency of which may increase overtime as they do not have prophylactic effect on the occurrence of lower extremity DVT and in situ IVCs thrombosis, and they may favor the devetopment of PTS ${ }^{17}$. In addition, the rates of IVCF thrombosis and recurrent DVT are highly variable, and the longterm efficacy of many IVCFs remains unknown ${ }^{16}$. Inthe 
PREPIC study, initially published in 1998 included 400 patients with DVT, the insertion of IVCF in combination with standard anticoagulation was associated with reduction in the occurrence of PE alone, but filters showed no impact in mortality ${ }^{18}$. In 8-year follow-up, after the insertion of filter in patients with proximal DVT with or without $P E^{19}$, the latter entity was reduced significantly, although not eliminated compared with patients without filters. However, these benefits were offset by an increase occurrence of DVT the in lower limbs; interestingly, in this study, IVCFs did not increase the risk of PTS. In our study, we observed that $5(9 \%)$ of our patients had recurrent thrombotic events in contrast with the $38 \%$ reported in literature, where the main risk factor was history of malignancy ${ }^{20}$.

In 2008, Ray and Prochazka published a meta-analysis; in this study, the authors observed a trend toward decreased VTE rates in patients with post-filter anticoagulation (12.3\% vs. $15.8 \%$ ), but the analysis failed to reach statistical significance ${ }^{21}$. In 2015, update of the PREPIC study group was confirmed that the use of retrievable IVCF in patients who can receive anticoagulation was not superior to anticoagulation alone ${ }^{22}$. In 2017, Yunes and Aizman completed a meta-analysis that included three systematic reviews and four clinical trials, the authors concluded that might not exist a difference in the occurrence of DVT adding an IVFC in patients on anticoagulation, and they could not find difference in regard to the occurrence of PE and mortality due to the low level of evidence available ${ }^{23}$, as we found in our study.

With respect the type of anticoagulation, Decousus et al. classified the patients in two groups: one with the unfractionated heparin and the second group with LMWH; the authors observed similar efficacy in both, without significant difference regarding the number of recurrent thrombotic events, hemorrhagic complications, or mortality ${ }^{18}$. Iwamoto et al. followed IVCF patients ranging from 1 to 9 years, during this study period, the author demonstrated that underlying diseases and the presence of cardiac thrombus were significant factors for the prognosis of patients with DVT who underwent IVCF with anticoagulation therapy ${ }^{24}$. In 2010, Hadjuk et al. published a prospective study that included 121 patients; the authors concluded that patients who have received IVCF after thromboembolic episodes and receive anticoagulation when it is not contraindicated and undergoes appropriate management have an acceptable prognosis if it not otherwise limited by cancer or VTE-unrelated terminal cardiopulmonary disease $^{12}$. In our series, anticoagulation therapy did not have an impact in survival and mortality was associated to malignancies. In 2014, Akl et al. ${ }^{25}$ published a comprehensive search for studies of anticoagulation in tients with cancer; this study included an electronic search of the Cochrane Central Register of Controfled Trials. The authors concluded that for long-term treatment of VTE in cancer patients, LMWH compared With Vitamin $\mathrm{K}$ antagonist reduces venous thromboembolic events but not mortality. In addition, the authors emphasized that the decision for a patient with cancerand history VTE to start long-term LMWH versus oral änticoagulation should balance the benefits and harms and integrate the patient's values and preferences for the important outcomes and alternative management. In 2016, Kang et al. published a retrospective study including 180 patients with cancer-associated PE, wwith 143 of them receiving and a total of 37 not receiving post-IVCF anticoagulation treatment, this study showed no difference in mortality in both groups ${ }^{26}$. In our stüdy, 8 of 25 patients with malignancies were initiated on anticoagulation, during the follow-up period, there were two recurrent thrombotic events, these two patients were on Vitamin $\mathrm{K}$ antagonist and new oral anticoâgulants, respectively. Due to the retrospective nature of our study, this variable was not in our control, but this supports the need of appropriate drug selection in this group of patients. Other important issues are the complications related directly with the device itself; there are numerous reports of IVCF dislodgement, vessel perforation or rupture ${ }^{9}$, and even device migration to the right ventricle as the report by Peters et al. ${ }^{27}$.

Although removal can be performed by endovascular means, in cases of perforation or migration, open surgery is sometimes necessary with a significant mörbidity in this frail population ${ }^{28}$. In a retrospective study that included 265 IVCF patients that underwent compüted tomography, $39 \%$ of them had IVCF penetration in the vessel wall and $13.2 \%$ to surrounding organs as the duodenum, aorta, vertebral bodies, muscles, pancreas, liver, diaphragm, and suprarenal glands ${ }^{29}$. Complications that occurred in our study included IVC rupture in $2(4 \%)$ patients, $1(2 \%)$ case of device migration, 5 (9\%) experienced recurrent thrombotic events, and $26 \%$ (14 patients) of the population developed PTS. In the MAUDE database, the adverse effects of IVCF Were reported; the BARD filters had complications in $27 \%$ of the cases, wall penetration occurred in $30 \%$ with celect IVCF. Failure during device deployment and placement occurred with OptEase in $30 \%$ and $45 \%$ of the cases with the Günter Tulip, the most common complication in the registry was device malfunction in $47 \%$ of patients ${ }^{30}$. 
These adverse effects could be related to the design of the devices and operator skills and experience.

We recognized limitations in our study, including the retrospective nature, non-randomized studied subjects, the relatively small number, and the differences of the comorbidities of studied groups.

\section{Conclusions}

Our initial observations suggest that in patients with IVCF in whom an optimal and structured anticoagulation therapy regime had equivalent rates of thrombotic events, device-related complications as vessel rupture, perforation, and filter migration than in those patients NA. In addition, anticoagulation therapy showed no impact in long-term survival. Further research in this area is warranted.

\section{Conflicts of interest}

None.

\section{Funding}

None.

\section{Ethical disclosures}

Protection of human and animal subjects. The authors declare that no experiments were performed on human or animals for this study.

Confidentially of data. The authors declare that they have followed the protocols of their work center on the publication of patient data.

Right to privacy and informed concent. The authors declare that the patient data is reported anonymously and informed for consent was waived.

\section{References}

1. Rajasekhar A. Inferior vena cava filters: current best practices. J Thromb Thrombolysis. 2015;39:315-27.

2. Wells PS, Forgie MA, Rodger MA. Treatment of venous thromboembolism. JAMA. 2014;311:717-28.

3. Lindblad B, Eriksson A, Bergqvist D. Autopsy-verified pulmonary embolism in a surgical department: analysis of the period from 1951 to 1988. Br J Surg. 1991;78:849-52.

4. Büller HR, Agnelli G, Hull RD, et al. Antithrombotic therapy for venous thromboembolic disease: the seventh ACCP conference on antithrombotic and thrombolytic therapy. Chest. 2004;126:401S-28.
5. Shackford SR, Cook A, Rogers FB, Littenberg B, Osler T. The increasing use of vena cava filters in adult trauma victims: data from the American college of surgeons national trauma data bank. J Trauma. 2007;63:764-9.

6. Rajasekhar A Streiff MB. Vena cava filters for management of venous thromboembolism: a clinical review. Blood Rev. 2013;27:225-41.

7. Isogai $\mathrm{T}$, Yasunaga $\mathrm{H}$, Matsui $\mathrm{H}$, et al. Effectiveness of inferior venaccava filters on mortality as an adjuvant to antithrombotic therapy. Am JMed. 2015;128:312.e23-31.

8. Weinberg I, Abtahian F, Debiasi R, et al. Effect of delayed inferior vena cava filter retrieval after early initiation of anticoagulation. Am $\mathrm{J}$ Cardiol. 2014:113:389-94

9. Hinojosa CA, Torres-Machorro A, Lizola R, Anaya-Ayala JE. Open removal of a retained retrohepatic inferior vena cava filter with a residual primary heuroectodermal renal tumoral thrombus. BMJ Case Rep. 2015;2015:bcr2015212190.

10. Hinojosa CA, Lizola R, Laparra-Escareno H, Anaya-Ayala JE. Endovascular recanalisation of a chronic occlusion of the retrohepatic IVC associated to a filter in a patient with antiphospholipid syndrome. BMJ Case Rep. 2017;2017:bcr-2016-218697.

11. Weinberg I, Kaufman J, Jaff MR. Inferior vena cava filters. JACC Cardiovasc Interv. 2013;6:539-47.

12. Hajduk B, Tomkowski WZ, Malek G, Davidson BL. Vena cava filter-occlusion and venous thromboembolism risk in persistently anticoagulated patients: a prospective, observational cohort study. Chest. 2010;137:877-82.

13. Girard $P$, Stern JB, Parent F. Medical literature and vena cava filters: so far so weak. Chest. 2002;122:963-7.

14. Schutzer R, Ascher E, Hingorani A, Jacob T, Kallakuri S. Preliminary results of the new $6 \mathrm{~F}$ trapease inferior vena cava filter. Ann Vasc Surg. 2003:17:103-6.

15. Keeling WB, Haines K, Stone PA, et al. Current indications for preoperative inferior vena cava filter insertion in patients undergoing surgerfy for morbid obesity. Obes Surg. 2005;15:1009-12.

16. Patel $\mathrm{SH}$, Patel $\mathrm{R}$. Inferior vena cava filters for recurrent thrombosis: current evidence. Tex Heart Inst J. 2007;34:187-94.

17. StreiffMB. Vena caval filters: a comprehensive review. Blood. 2000;95:3669-77.

18. Decousus $H$, Leizorovicz A, Parent $F$, et al. A clinical trial of vena caval filters in the prevention of pulmonary embolism in patients with proximal deep-vein thrombosis. Prévention du risque d'embolie pulmonaire-par interruption cave study group. N Engl J Med. 1998;338:409-15. (I)

19. PREPIC Study Group. Eight-year follow-up of patients with permanent vena cava filters in the prevention of pulmonary embolism: the PREPIC (prevention du risque d'embolie pulmonaire par interruption cave) randomized study. Circulation. 2005;112:416-22.

20. Ren W, Li Z, Fu Z, Fu Q. Analysis of risk factors for recurrence of deep venous thrombosis in lower extremities. Med Sci Monit. 2014;20:199-204.

21. Ray CE Jr., Prochazka A. The need for anticoagulation following inferior vena cava filter placement: systematic review. Cardiovasc Intervent Radiol. 2008;31:316-24.

22. Mismetti $\mathrm{P}$, Laporte $\mathrm{S}$, Pellerin $\mathrm{O}$, et al. Effect of a retrievable inferior vena cava filter plus anticoagulation vs anticoagulation alone on risk of recurrent pulmonary embolism: a randomized clinical trial. JAMA. 2015;313:1627-35

23. Yunes A, Aizman A. Is it worth adding an inferior vena cava fifter to anticoagulation in thromboembolic disease? Medwave. 2017:17:e6935.

24. Iwamoto $Y$, Okamoto $M$, Hashimoto $M$, et al. Clinical outcomes- and causes of death in Japanese patients with long-term inferior vena cava filter implants and deep vein thrombosis. J Cardiol. 2014:64:308-11.

25. Akl EA, Kahale L, Barba M, et al. Anticoagulation for the long-term treatment of venous thromboembolism in patients with cancer. Cochrane Database Syst Rev. 2014;7:CD006650.

26. Kang J, Kim SO, Oh YM, Lee SD, Lee JS. Effect of post-filter anticoagulation on mortality in patients with cancer-associated pulmonary embolism. Int J Clin Oncol. 2018;23:1007-13.

27. Peters MN, Khazi Syed RH, Katz MJ, et al. Inferior vena cava filter migration to the right ventricle causing nonsustained ventricular tachycardia. Tex Heart Inst J. 2013;40:316-9.

28. Thornburg K, Obmann M, Batool A, Nikam S, Mariner D. Percutaneous retrieval of an inferior vena cava filter causing right ureter obstruction. Ann Vasc Surg. 2014;28:122.e11-3.

29. Zhou D, Moon E, Bullen J, et al. Penetration of celect inferior vena cava filters: retrospective review of CT scans in 265 patients. AJR Am J Roentgenol. 2014;202:643-7.

30. Andreoli JM, Lewandowski RJ, Vogelzang RL, Ryu RK. Comparison of complication rates associated with permanent and retrievable inferior vena cava filters: a review of the MAUDE database. J Vasc Interv Radiol. 2014;25:1181-5. 